$\begin{array}{ll}\text { Abstracta Iranica } & \begin{array}{l}\text { Abstracta Iranica } \\ \text { Revue bibliographique pour le domaine irano-aryen }\end{array} \\ & \text { Volume } \mathbf{3 0} \mid \mathbf{2 0 1 0} \\ & \text { Comptes rendus des publications de } \mathbf{2 0 0 7}\end{array}$

\title{
Refiguring Unani Tibb. Plural Healing in Late Colonial India. New Delhi, Orient Longman, 2007, 316 p.
}

\section{Fabrizio Speziale}

\section{(2) OpenEdition}

1 Journals

\section{Édition électronique}

URL : http://journals.openedition.org/abstractairanica/37972

DOI : 10.4000/abstractairanica.37972

ISSN : 1961-960X

Éditeur :

CNRS (UMR 7528 Mondes iraniens et indiens), Éditions de l'IFRI

\section{Édition imprimée}

Date de publication : 8 avril 2010

ISSN : 0240-8910

\section{Référence électronique}

Fabrizio Speziale, «Refiguring Unani Tibb. Plural Healing in Late Colonial India. New Delhi, Orient Longman, 2007, 316 p. », Abstracta Iranica [En ligne], Volume 30 | 2010, document 239, mis en ligne le 08 avril 2010, consulté le 26 septembre 2020. URL : http://journals.openedition.org/abstractairanica/ 37972 ; DOI : https://doi.org/10.4000/abstractairanica.37972

Ce document a été généré automatiquement le 26 septembre 2020.

Tous droits réservés 


\title{
Refiguring Unani Tibb. Plural Healing in Late Colonial India. New Delhi, Orient Longman, 2007, 316 p.
}

\author{
Fabrizio Speziale
}

1 L'histoire de l'école de la médecine avicennienne dans le sous-continent indien, où elle est appelé yūnānī țibb (médecine grecque), ou unani dans la forme anglicisée, reste encore un sujet assez peu étudié par rapport au développement que cette tradition scientifique a connu en Inde musulmane. Cet ouvrage de Guy Attewell offre une contribution importante à l'étude de la médecine avicennienne en Inde à l'époque coloniale, se concentrant notamment sur la période entre la fin du XIX ${ }^{e}$ s. et le début du $\mathrm{XX}^{\mathrm{e}}$. L'ouvrage examine une période qui est marquée par des réformes très importantes de l'identité scientifique de la médecine unani, qui étaient en premier lieu une conséquence de la confrontation avec l'hégémonie du savoir scientifique et de la technologie coloniales. Il s'agit d'une période cruciale, qui vit la disparition d'une grande partie du patronage royal vers la médecine traditionnelle, la naissance de nouvelles institutions unani empruntées aux modèles coloniaux, la diffusion de l'imprimerie, le passage du persan élitiste à l'ordou plus populaire dans l'enseignement et dans la littérature médicale, dynamiques qui minaient les anciennes hiérarchies de la tradition, gravitant principalement autour de l'autorité assignée à l'instruction privée et à la transmission du savoir au sein des familles. Cela en tout cas, comme le montre très bien l'A., ne se réalisa pas de façon uniforme et soudaine, et certains des moyens fondamentaux qui devaient réformer et moderniser la tradition, comme les nouveaux collèges unani empruntés aux écoles coloniales, étaient au début des institutions ambiguës qui ne furent pas vraiment capables de se substituer au rôle et à l'autorité des familles. Cette période de transformation est analysée notamment par rapport à certains domaines spécifiques : les réactions et les stratégies des médecins unani face aux épidémies de peste, examinées dans le deuxième chapitre (pp. 50-95); les efforts des médecins unani pour se coaliser avec leurs collègues ayurvédiques dans les nouvelles associations professionnelles visant à défendre le statut des médecins traditionnels, analysés dans le troisième chapitre (pp. 147-192) ; le cinquième chapitre 
(pp. 193-237) est dédié au discours médical sur les femmes, leur pédagogie médicale et leurs traitements, sujets sur lesquels d'importants traités apparaissent en ourdou. L'étude de Guy Attewell offre en outre une analyse excellente du rôle joué à cette époque par les nouvelles revues de médecine unani publiées en ourdou.

INDEX

Thèmes : 10. Histoire des Sciences et des Techniques

\section{AUTEURS}

FABRIZIO SPEZIALE

Pontificia Università Gregoriana - Rome 